\title{
Alteration of DSS-mediated immune cell redistribution in murine colitis by oral colostral immunoglobulin
}

Peggy Bodammer ${ }^{1,2^{*}}$, Elisabeth Zirzow ${ }^{1}$, Sebastian Klammt ${ }^{3}$ Claudia Maletzki $^{4}$ and Claus Kerkhoff ${ }^{2}$

\begin{abstract}
Background: Oral bovine colostrum prophylaxis accelerates the recovery of dextran sulfate sodium (DSS)-induced colitis. In the present study the beneficial effects on acute intestinal inflammation of two major colostral components, secretory immunoglobulin A and lactoferrin, were investigated. Outbred NMRI mice received whole bovine colostrum (BC, $20 \mathrm{mg} / \mathrm{kg}$ body weight), colostral bovine lactoferrin (bLf, $150 \mathrm{mg} / \mathrm{kg}$ ), or secretory immunoglobulin A (slgA, 1-2 mg/kg body weight) daily by oral gavage, either two weeks before induction of colitis (prophylaxis) or after disease establishment (therapy). Bovine serum albumin (BSA, $150 \mathrm{mg} / \mathrm{kg}$ body weight) and immunoglobulin $\mathrm{G}$ (lgG, 1 and $2 \mathrm{mg} / \mathrm{kg}$ body weight) served as protein controls. Colitis was induced by providing 5\% DSS solution ad libitum for seven days.

Results: Compared to BSA, BC therapy improved occult blood, stool consistency, and clinical recovery from colitis but did not prevent initial weight loss. In contrast, administration of bLf did not influence the course of colitis in either the prophylactic or the therapeutic setting. Therapeutic application of slgA promoted weight gain in the recovery phase of colitis but failed to improve other clinical parameters. Prophylactically-fed slgA influenced immune cell redistribution, normalized peripheral blood $\mathrm{CD}_{11} \mathrm{c}^{+} \mathrm{CD} 3^{+}$mature dendritic cells, modulated colonic immune cell infiltration, and altered the numbers of both DSS-induced regulatory $\gamma \delta \mathrm{TCR}^{+} \mathrm{T}$ cells and $\mathrm{CD} 11 \mathrm{~b}^{+} \mathrm{Gr}-1^{+}$ myeloid suppressor cells in the lymph nodes and spleens of mice.

Conclusions: These data demonstrated the potential of colostrum in disease recovery and epithelial homeostasis following intestinal injury. Colostral slgA failed to improve acute disease activity but promoted weight gain and modulated immune cell responses that are involved in the genesis of colitis.
\end{abstract}

Keywords: DSS-colitis, Recovery, Colostrum, Secretory immunoglobulin A, Bovine lactoferrin, $\gamma \delta$ - T-cells Myeloid-derived suppressor cells, Outbred NMRI mice

\section{Background}

Crohn's disease and ulcerative colitis are chronic inflammatory disorders of the gut that cause major life-long disability. Afflicting mostly young people at an age when they are most active both in their private and professional life, inflammatory bowel disease (IBD) represents an important

\footnotetext{
* Correspondence: peggy.bodammer@uni-rostock.de

'Division of Gastroenterology, Department of Medicine II, University of Rostock, Rostock 18057, Germany

${ }^{2}$ Department of Immunology, Project group "Extracorporal

Immunomodulation", Fraunhofer Institute for Cell Therapy and Immunology,

Rostock 18057, Germany

Full list of author information is available at the end of the article
}

public health problem affecting the patients education, working abilities, social life and quality of life. The cause of IBD is multiple and so far not completely understood. However, genetic factors, environmental factors and the gut bacteria play a role in disease development.

Conventional therapy of active IBD pre-dominantly target anti-inflammatory immune responses, largely due to cytokine release within the intestine. Thus, therapeutic treatment mainly includes anti-inflammatory drugs, immunosuppressants, biologic agents, and antibiotics [1]. However, these agents may cause severe adverse effects and are therefore not suitable for long-term treatment of IBD. Moreover, conventional drugs block manifestation or consequences of inflammation in acute disease. Thus,

\section{Biomed Central}


there is a necessity for therapeutic strategies that target improvement of impaired barrier function in remission. Suitable candidates are dietary supplements and food components such as colostrum. Although natural therapies are commonly associated with lower toxicity and fewer side effects than conventional drugs, the scientific proof of their effectiveness and safety is demanded [2].

Colostrum, the secretion produced by the mammary glands during the first three days post-partum, contains many functional nutrients. These include immunoglobulins, growth factors, and antimicrobial peptides. The potential of colostrum to affect gastrointestinal infections and to reduce the incidence of immune-mediated diseases is well established $[3,4]$. In accordance with this, we recently demonstrated the protective effect of orally applied colostrum in a murine colitis model [5]. Beneficial effects were characterized by improvement of clinical colorectal inflammation symptoms and by the induction of immunoregulatory mechanisms, predominantly of the innate immune system arm. Thus, identification of factors responsible for preventing experimental colitis might provide the basis for developing a long-term treatment regimen.

In IBD patients, local production of polymeric IgA (pIgA) is altered and this affects both immunological homeostasis and humoral immune responses [6,7]. IgA does not activate the classical complement pathway and inhibits the production of pro-inflammatory cytokines in response to lipopolysaccharide (LPS), thereby maintaining mucosal integrity [8]. SIgA preparations from colostrum are active against various microbial antigens and inhibit adhesion and invasion by enteropathogenic Escherichia coli in vitro $[9,10]$. Colostral sIgA influences the development of the gastrointestinal immune system in milk-fed infants; however, little is known about the effectiveness of oral sIgA in maintaining gut barrier functions in adults.

Another colostral peptide with a broad range of immunomodulatory properties is lactoferrin (Lf), a member of the iron-binding glycoprotein family. Lf is predominately found in mucosal secretions and neutrophilic granules [11]. Lf concentration and iron saturation differ among species; bovine (bLf) and human (hLf) Lfs show strong sequence homology [12]. BLf has been reported to stimulate mucosal and systemic immune responses when given orally $[13,14]$. Moreover, there is experimental evidence that Lf reduces the severity of colitis in rodents $[15,16]$.

In the present study, we explored the potential of orally applied colostral bLf and sIgA for modulating immune responses and recovery from dextran sodium sulfate (DSS)-induced murine colitis. Whole bovine colostrum (BC) improved the clinical severity of colitis, whereas bLf had no effect. SIgA influenced DSS-mediated immune cell redistribution and specifically altered colonic cell infiltration. Therefore, it might be an interesting candidate for promoting regeneration from acute colitis.

\section{Results}

Therapeutic application of colostrum and slgA improved clinical recovery from colitis

After a single seven-day treatment of 5\% DSS in drinking water, the mice showed signs of acute colitis including weight loss, bloody stools, and diarrhea. During the induction phase of colitis, neither the treatment (BC, sIgA, bLf) nor the control ( $\mathrm{NaCl}, \mathrm{IgG}, \mathrm{BSA})$ groups differed significantly with respect to body weight (Figure 1A). However, disease activity in the acute phase of inflammation (day 4 to day 7) declined only after $\mathrm{BC}$-feeding owing to reduced occult blood ( $\mathrm{P}=0.008$ vs. BSA, Figure $1 \mathrm{C})$ and enhanced stool consistency $(\mathrm{P}=0.028$ vs. BSA, Figure $1 \mathrm{D})$.

During the recovery phase, mice receiving therapeutic sIgA gained more weight than controls receiving $\mathrm{NaCl}$ $(\mathrm{P}=0.077)$ or BSA $(\mathrm{P}=0.002)$. $\mathrm{BC}$ and bLf showed only marginal differences from the control groups $(\mathrm{NaCl}, \mathrm{IgG}$, BSA). Since BSA-fed mice showed the most dramatic weight loss, up to $20 \%$ at day 14 , the BC- and sIgAinduced recovery was not simply attributable to a feeding effect (Figure 1B).

\section{Therapeutic application of colostrum or colostral components had no effect on histopathological severity of colitis}

In contrast to the clinical benefit, BC and sIgA did not reduce colon shortening at day 15 after DSS challenge. In all experimental groups, colon lengths were significantly lower than those in controls not treated with DSS (see Additional file 1). Histological examination of the colon at day 15 revealed no significant differences in total histological score or in grade and extent of inflammation (see Additional file 1).

\section{Therapeutic application of slgA affected immune cell redistribution}

The induction of colitis is characterized by a reduced number of mature $\mathrm{CD} 11 \mathrm{c}^{+} \mathrm{CD} 83^{+}$dendritic cells (DCs) in the periphery and spleen and by a raised level in the mesenteric lymph nodes. Therapeutic application of Igs normalized the distribution of $\mathrm{CD} 11 \mathrm{c}^{+} \mathrm{CD} 83^{+}$cells compared to $\mathrm{NaCl}$ controls by increasing their numbers in the spleens of sIgA-fed and in the peripheral blood of IgG-fed mice. Inflammation-induced elevation of DCs in mesenteric lymph nodes was exclusively found in $\mathrm{NaCl}$ controls; their numbers were not altered in the therapeutic groups (Figure 2A). In addition to DCs, $\gamma \delta \mathrm{TCR}^{+}$ $\mathrm{T}$ cells are significantly influenced by DSS-induced colitis [5], and the levels of this cell population were higher in the mesenteric lymph nodes and spleens of DSSexposed mice than in untreated controls. However, except in the case of IgG, therapeutic application of BC or Lf did not significantly alter the DSS-mediated cell redistribution (Figure 2B). Taking these findings together, the 

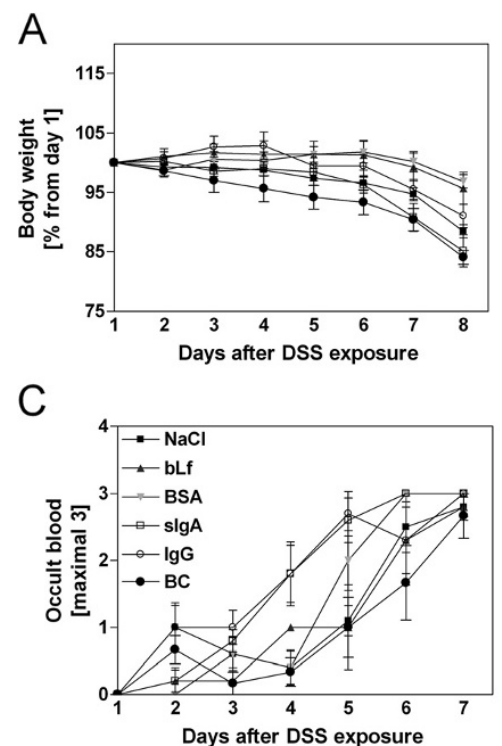

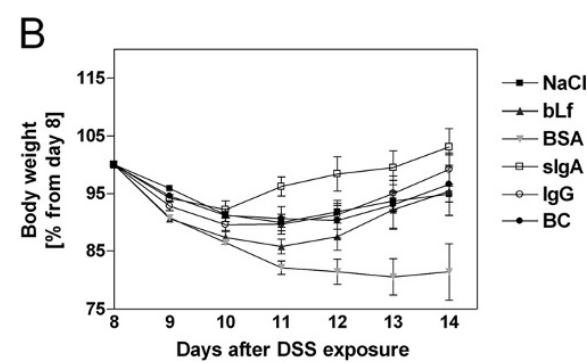

D

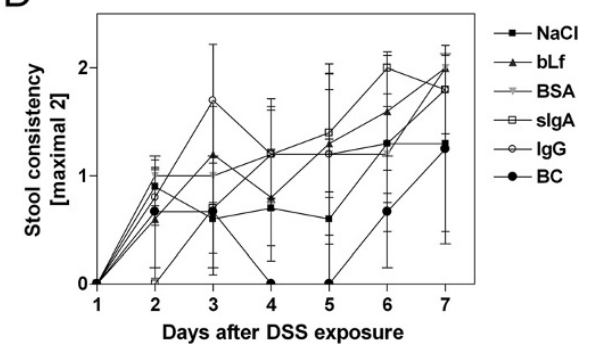

Figure 1 Influence of therapeutically applied colostral compounds on clinical severity of DSS-induced colitis. The indicated therapeutics (bLf, slgA, IgG, and BC) and controls ( $\mathrm{NaCl}$ and BSA) were applied parallel to DSS treatment. Weight loss was either represented during the induction phase of colitis as percentage of body weight from day 1 (A) or during the recovery phase as percentage from day 8 (B). Clinical disease activity was determined by scoring changes in body weight, occult blood (C) and stool consistency (D) as shown in Additional file 3. Values are means $\pm S D$ of $n=8(\mathrm{NaCl}), n=6(B C, \operatorname{slg} A, \operatorname{lgG})$, and $n=5$ (bLf, BSA) mice.

observed clinical benefit of sIgA treatment could partly be explained by systemic immunological alterations.

\section{Effect of prophylactically applied secretory IgA on clinical severity of colitis}

Next, we analyzed the potential of $\operatorname{sgA}$ in a prophylactic setting. IgG served as control and $\mathrm{BC}$ as positive control. During the feeding period, sIgA and IgG were well tolerated by all mice and no side effects such as lethargy, abdominal pain or diarrhea were observed. Initial weight loss from day 1 to day 7 remained unchanged in all experimental groups (Figure 3A). In the recovery phase, weight gain was enhanced within the $\mathrm{BC}$ group until the end of the experiments (Figure $3 \mathrm{~B}$ ), and $\mathrm{BC}$ ameliorated clinical DAI ( $\mathrm{P}=0.025$ vs. IgG) owing to improved stool consistency ( $\mathrm{P}=0.045$ vs. IgG) (Figure $3 \mathrm{C}$ and $\mathrm{D}$ ). Clinical recovery did not differ significantly between sIgA- and IgG-fed mice (Figure 3B and C).
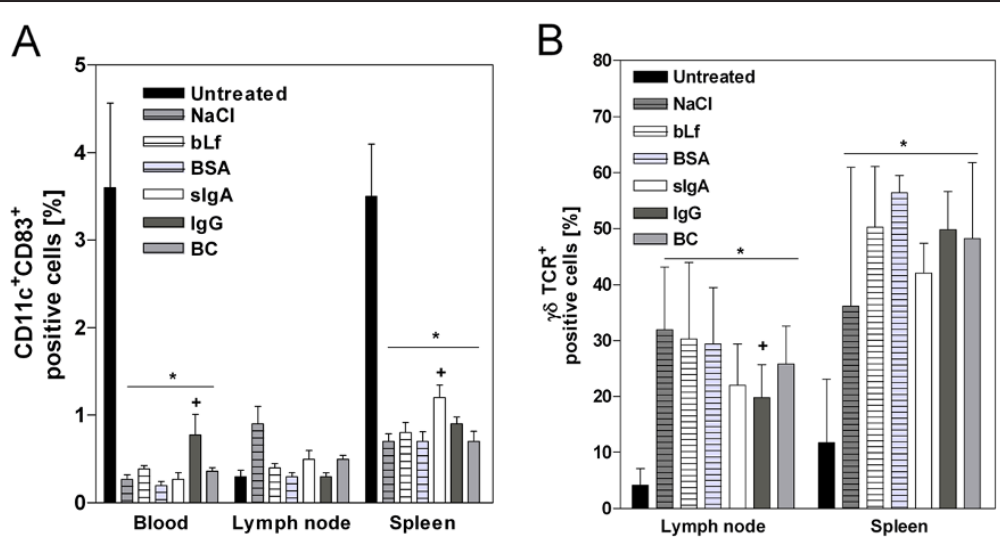

Figure 2 Leukocyte distribution in peripheral blood, lymph nodes and spleen at day 15 after starting DSS exposure. The indicated therapeutics (bLf, slgA, lgG, and BC) and controls ( $\mathrm{NaCl}$ and BSA) were applied parallel to DSS treatment. The untreated group represents healthy animals without any intervention. Values are presented as percent positive $\operatorname{CD}_{11 C^{+}} \operatorname{CD}_{3} 3^{+}(\mathbf{A})$ or $\gamma \delta \operatorname{TCR}^{+}(\mathbf{B})$ of 10,000 measured events and given as mean $\pm S D ; n=12$ (Untreated) $n=8(\mathrm{NaCl}), n=6\left(B C\right.$, slgA, lgG), and $n=5$ (bLf, BSA). ${ }^{*} p<0.05$ vs. Untreated; $+p<0.05$ vs. NaCl, Mann Whitney U-test. 

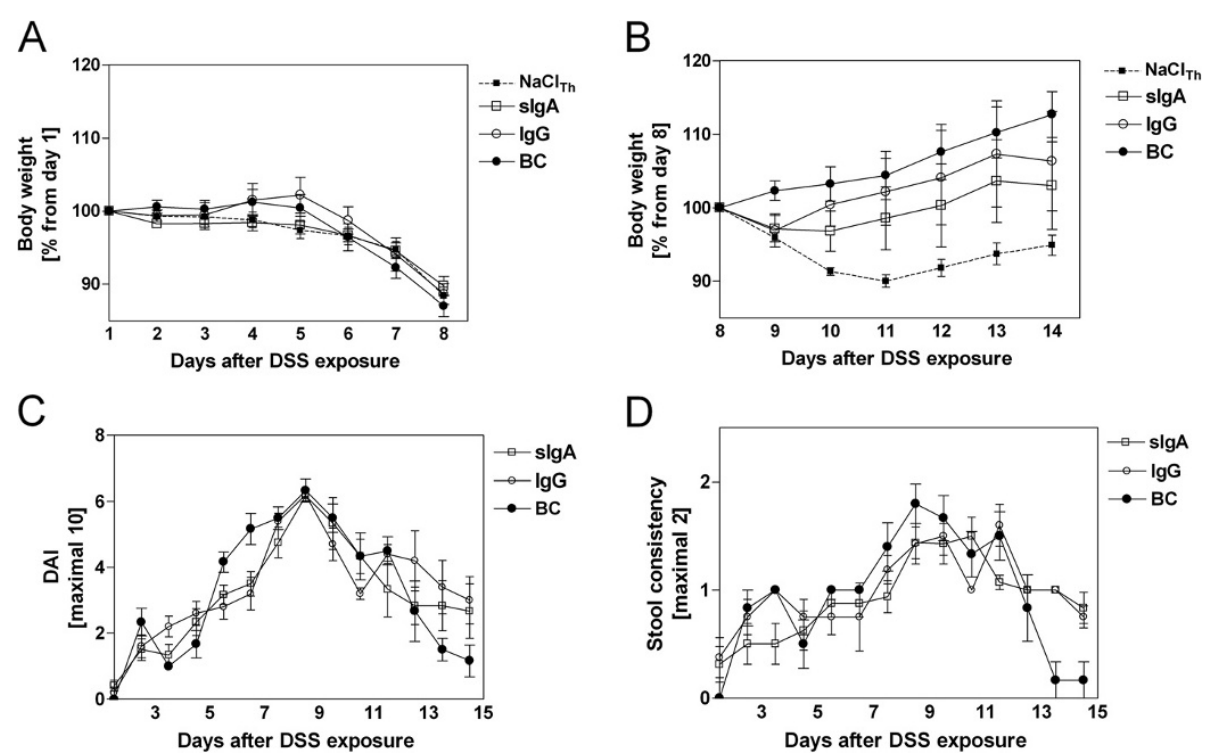

Figure 3 Influence of prophylactically applied immunoglobulins and whole BC on clinical severity of DSS-induced colitis. The indicated therapeutics (slgA, lgG, and BC) and control ( $\mathrm{NaCl})$ were applied parallel to DSS treatment. Negative control was represented from the therapeutic setting $\left(\mathrm{NaCl}_{\mathrm{Th}}\right)$. Weight loss was either shown during the induction phase of colitis as percentage of body weight from day $1(\mathbf{A})$ or as weight loss during the recovery phase as percentage body weight from day 8 (B). Clinical disease activity (DAI) (C) was determined by scoring changes in body weight, occult blood and stool consistency (D) as described in the Methods section. Values are mean $\pm S D$ of $n=8(\mathrm{NaCl}$ Th $), n=6(B C)$, $n=6-8(\lg A)$, and $n=5-8(\lg G)$ mice.

\section{Prophylactic application of secretory IgA failed to} improve histopathological changes of colitis but affected colonic cell infiltration

Colon length (data not shown) and total median histological score did not differ significantly among any of the DSS-exposed experimental and untreated control groups (see Additional file 2). Therefore, a detailed immunohistochemical analysis from colonic sections was performed to unravel the observed clinical benefit (Figure 4A). The numbers of $\mathrm{CD}^{+}$and $\gamma \delta \mathrm{TCR}^{+} \mathrm{T}$ cells and of $\mathrm{CD} 11 \mathrm{c}^{+}$ and $\mathrm{CD} 83^{+}$mature dendritic cells were markedly higher in the BC and sIgA groups than in IgG-fed mice (Figure 4B). These data argued for a specific local immune modulation by $\mathrm{BC}$ and colostral sIgA.

\section{Prophylactically applied secretory IgA normalized DSS- mediated redistribution of immune cells}

We next examined whether immunological effector cells were influenced by sIgA in other lymphatic organs. Prophylactic application of sIgA normalized $\mathrm{T}$ cell numbers in spleen and mesenteric lymph nodes. Levels of $\mathrm{CD}^{+} \mathrm{CD}^{+}$ cells were similar to those in the untreated control mice. Interestingly, neither IgG nor BC affected $\mathrm{T}$ cell numbers, indicating a specific sIgA-mediated response (Figure 5A).

Comparable though less pronounced effects were observed for splenic $\gamma \delta \mathrm{TCR}^{+}$cells (Figure $5 \mathrm{~B}$ ). In mesenteric lymph nodes, a similar modulation of immune cell distribution was found. Here again, levels of mature

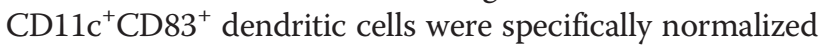

by sIgA prophylaxis (Figure $5 \mathrm{C}$ ). Taken together, these data clearly pointed to immunological alterations by sIgA prophylaxis that influenced colonic inflammation.

Prophylactically applied secretory IgA increased levels of DSS-induced myeloid-derived suppressor cells

Myeloid-derived suppressor cells (MDSC) represent another cell population that is altered during the course of colitis [5]. The MDSC population is heterogeneous and is characterized by $\mathrm{CD}_{11 \mathrm{~b}}{ }^{+}$and $\mathrm{Gr}^{+}$co-expression. These cells are induced by DSS exposure and accelerate recovery from colitis following transplantation [17]. Ac-

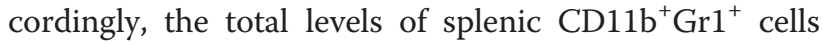
were higher in DSS-exposed mice than in healthy untreated controls on day 15 (Figure 6). While BC prophylaxis nearly normalized splenic $\mathrm{CD}_{11 \mathrm{~b}^{+} \mathrm{Gr}^{+}}$cell numbers, sIgA did not. In sIgA-fed mice, the numbers of MDSCs were massively increased (Figure 6A). It is notable that these effects were evident in all three subpopulations $\left(\mathrm{CD} 11 \mathrm{~b}^{+} \mathrm{Gr} 1^{\text {+low, int, high }}\right)$; MDSC levels were more than three-fold higher than in IgG and $\mathrm{BC}$ exposed mice (Figure 6B).

\section{Discussion}

As shown in a previous study, oral BC prophylaxis accelerates recovery from DSS-induced colitis [5]. However, most treatment regimens for IBD patients are not available before the onset of disease. Therefore, the present study was undertaken to evaluate the potential 


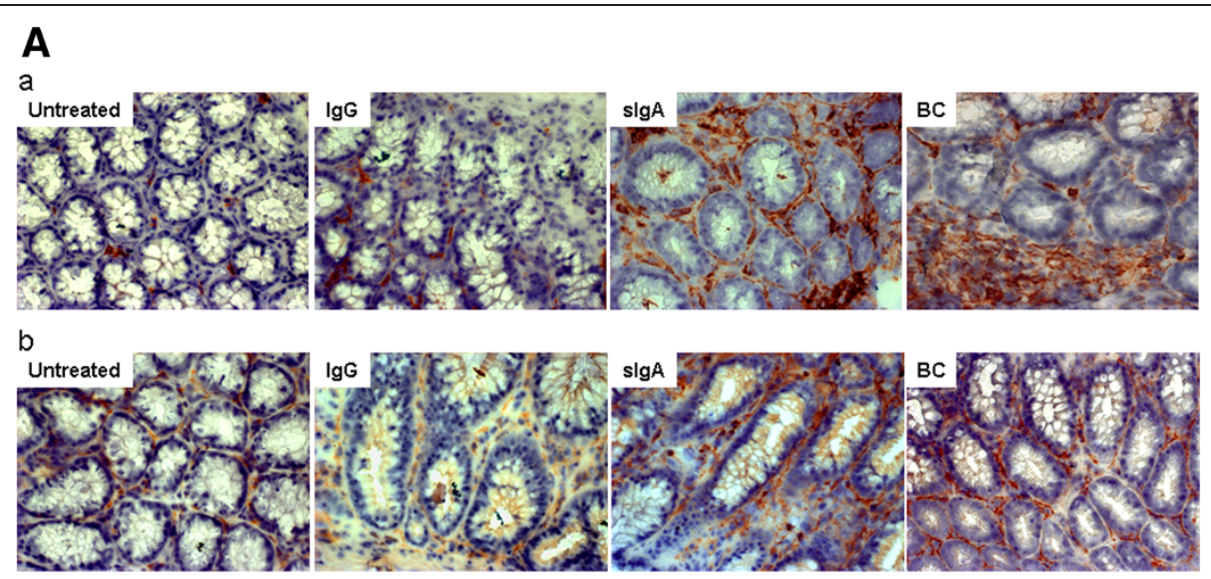

B

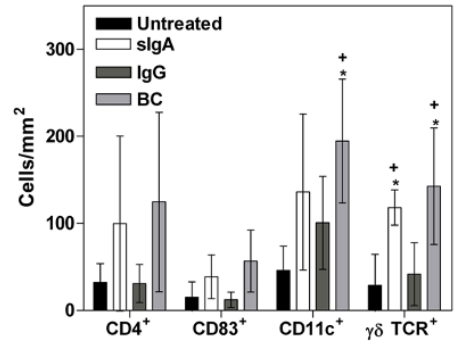

Figure 4 Colonic infiltration of prophylactically-fed, DSS-exposed mice and untreated control without intervention at day 15.

The indicated therapeutics (slgA, lgG, and BC) were applied parallel to DSS treatment. The untreated group represents healthy animals without any intervention. A: Immunohistochemical staining of a) $C D 11 c^{+}$mature dendritic cells or $\left.\mathbf{b}\right) \gamma \delta T C R^{+} T$-cells in the colon of DSS-exposed mice compared to untreated, healthy controls. Representative images are shown in 200-fold magnification. B: Impact of prophylactic slgA on cell distribution in lymph nodes and spleen at day 15. The indicated therapeutics (slgA, IgG, and BC) were applied parallel to DSS treatment. The untreated group represents healthy animals without any intervention. Values are given as percent $C D 3^{+} C D 4^{+}(A), \gamma \delta T C R^{+}(B)$, or $C D 11 c^{+} C D 83^{+}(C)$ positive cells of 10,000 measured events and given as mean \pm SD. $n=6-8$ (Untreated), $n=6$ (BC, slgA), and $n=5$ (IgG) mice. ${ }^{*} P<0.05$ vs. untreated, Mann Whitney U-test.Values are means \pm SD of $n=6$ (Untreated, BC, IgA) and $n=5$ (IgG) mice. ${ }^{*} P<0.01$ vs. untreated, ${ }^{+} P<0.05 \mathrm{vs}$. IgG, Mann Whitney U-test.
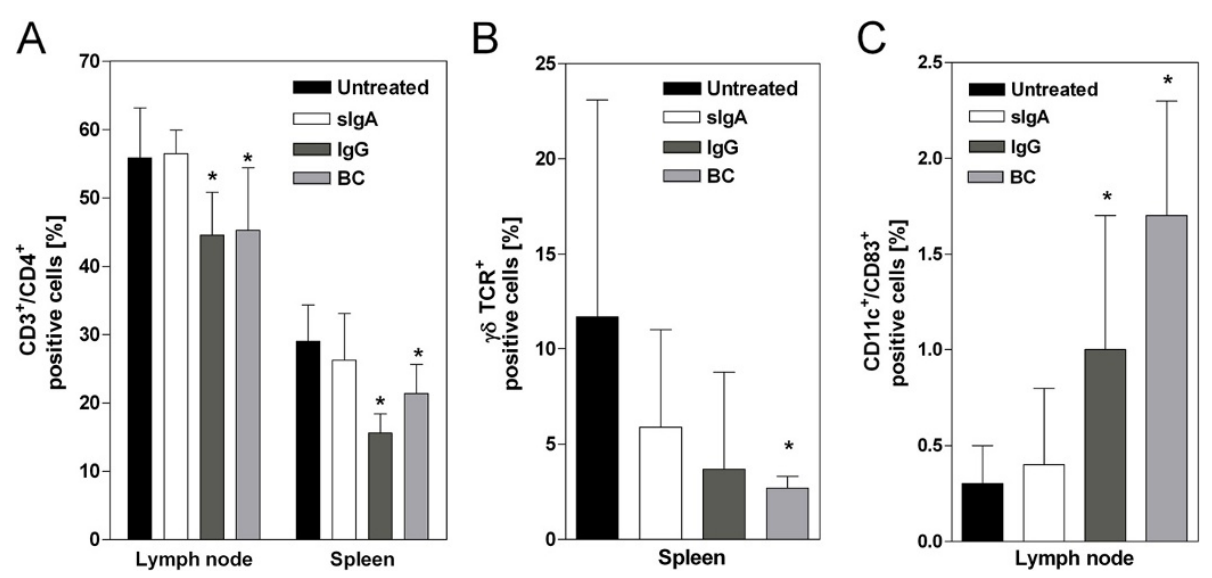

Figure 5 Impact of prophylactic slgA on cell distribution in lymph nodes and spleen at day 15. The indicated therapeutics (slgA, lgG, and BC) were applied parallel to DSS treatment. The untreated group represents healthy animals without any intervention. Values are given as percent $\mathrm{CD}^{+} \mathrm{CD}^{+}(\mathbf{A}), \gamma \delta \mathrm{TCR}^{+}(\mathbf{B})$, or $\mathrm{CD} 11 \mathrm{C}^{+} \mathrm{CD} 3^{+}(\mathbf{C})$ positive cells of 10,000 measured events and given as mean \pm SD. $\mathrm{n}=6-8$ (Untreated), $\mathrm{n}=6$ (BC, slgA), and $\mathrm{n}=5(\mathrm{lgG})$ mice. ${ }^{*} P<0.05$ vs. untreated, Mann Whitney U-test. 

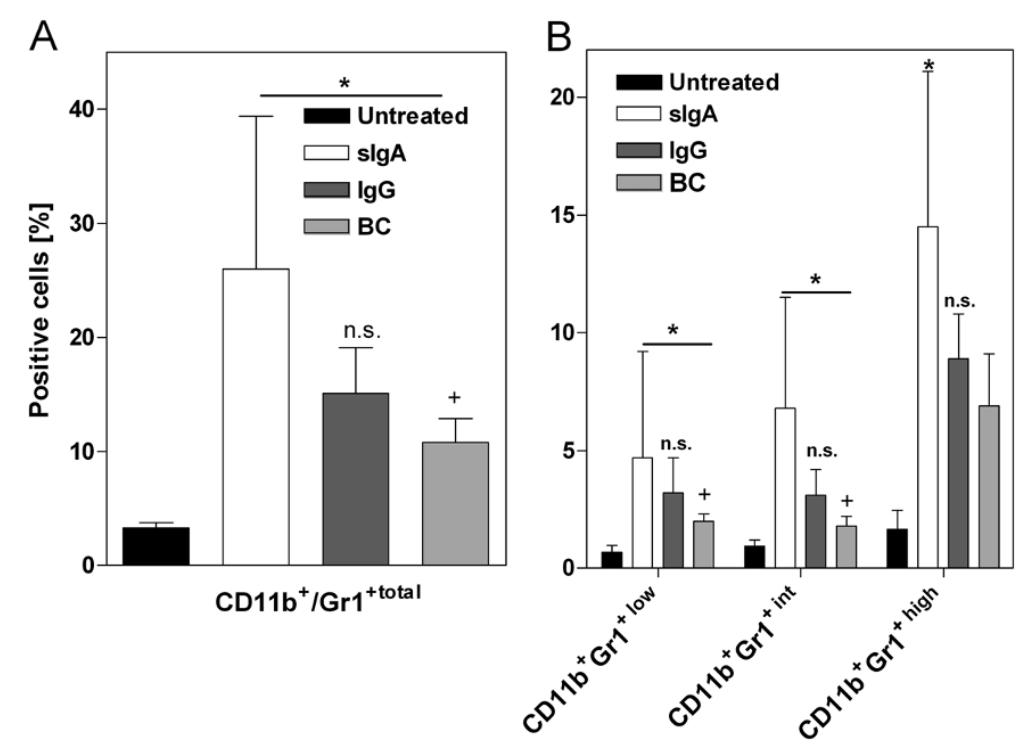

Figure 6 Impact of prophylactic slgA on DSS-induced myeloid-derived suppressor cells at day 15. The indicated therapeutics (slgA, IgG, and $\mathrm{BC}$ ) were applied parallel to DSS treatment. The untreated group represents healthy animals without any intervention. Values are provided as percent total $\mathrm{CD} 11 \mathrm{~b}^{+} \mathrm{Gr}-1^{+}$cells positive cells (A) or subpopulations with low, intermediate (int) or high $\mathrm{CD} 11 \mathrm{~b}^{+} \mathrm{Gr}-1^{+}$co-expression in 10,000 measured events (B). Values are given as mean \pm SD. $n=6-8$ (Untreated), $n=6\left(B C\right.$, slgA), and $n=5$ (lgG) mice. ${ }^{*} P<0.05$ vs. untreated, ${ }^{+} P<0.05$ vs. slgA, n.s. = not significant lgG vs. slgA, Mann Whitney U-test.

of whole BC and selected colostral compounds such as sIgA and bLf in a therapeutic setting. Both compounds display immunomodulatory potential $[6,11]$, are resistant against proteolytic degradation, and accumulate in blood and intestinal tissue of mice $[18,19]$.

The major finding of the study was that whole $\mathrm{BC}$ and in part colostral sIgA improved clinical recovery from colitis when applied therapeutically. This conclusion was confirmed by the enhanced weight gain of sIgA-fed mice and the lower disease activity (occult blood, diarrhea) in the $\mathrm{BC}$-fed treatment group. Although $\mathrm{BC}$ and sIgA prevented neither the initial weight loss after induction of colitis nor the histological outcome of colitis, sIgAand $\mathrm{BC}$-fed mice recovered more quickly than control animals. In striking contrast, bLf failed to improve the clinical and histological course of colitis after both therapeutic and prophylactic applications (data not shown). This was surprising since bLf showed anti-inflammatory potential in DSS-induced colitis and stimulated mucosal and systemic immune responses when given orally $[13,14]$. In addition, reduced LPS-induced epithelial damage and barrier destruction have been reported [20], as well as decreased rectal bleeding and an improved histological score [15]. These findings, seemingly contradictory to our study, could be attributed to the fact that in these studies, human Lf with $7 \%$ iron saturation level was applied perorally twice a day. In contrast, we used Lf derived from bovine colostrum, and the level of iron saturation of bovine Lf was in range of 5 to $30 \%$. Therefore, the discrepancy might be due to the therapeutic regimen rather than to the iron saturation level. Thus, increasing the number of Lf injections per day might have beneficial effects on the course of colitis. However, this was beyond the scope of the present study.

Another remarkable finding of our study was the effect of immunoglobulins on those immunological effector cells that most probably promote disease recovery. Ma-

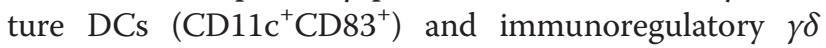
$\mathrm{TCR}^{+} \mathrm{T}$ cells were almost normalized in lymph nodes and spleens in the sIgA and IgG groups. Similar data were obtained in the prophylactic setting. SIgA almost normalized the DSS-mediated cell redistribution $\left(\mathrm{CD} 4^{+} \mathrm{T}\right.$ helper cells, $\gamma \delta \mathrm{TCR}^{+} \mathrm{T}$ cells, $\mathrm{CD} 11 \mathrm{c}^{+} \mathrm{CD} 83^{+}$mature dendritic cells) in lymph nodes and spleen.

Although $\gamma \delta$ T cells are important in intestinal inflammation, the functional role of this cell population remains unknown. Under physiological conditions, they represent a minor subset within lymph nodes and spleens; however, they are induced in mice and men by inflammatory responses [21,22]. Peripheral human $\gamma \delta$ T cells exert regulatory functions and suppress $\mathrm{T}$ helper cell proliferation [23]. Thus, the specific effects of sIgA on immune cell distribution can be regarded as favorable immune modulation of DSS-induced inflammation. In addition, colostral sIgA but not IgG influenced colonic cell infiltration. Just as whole BC is effective in preventing DSS-induced colitis, so sIgA treatment was characterized by massive increases in colonic $\mathrm{CD} 11 \mathrm{c}^{+}$and $\mathrm{CD} 83^{+} \mathrm{DCs}$ as well as $\gamma \delta \mathrm{TCR}^{+} \mathrm{T}$ cells. Thus, the increase of local regulatory cells after $\mathrm{BC}$ prophylaxis was most likely to have been due to colostral 
sIgA rather than IgG. Activated $\gamma \delta$ T cells have been shown to promote epithelial cell growth via the production of keratinocyte growth factor [24] and to regulate intestinal homeostasis [25], while depletion of $\gamma \delta$ T cells worsened inflammation in mouse models of colitis [26,27]. Therefore, in accordance with these studies, the enhanced recovery from colitis was most probably mediated by immune cell modulation through colostrum and in particular colostral sIgA.

In our previous study, we hypothesized that MDSCs contributed to the clinical benefit of prophylactically applied colostrum [5]. Here again, sIgA prophylaxis specifically increased the number of splenic CD $11 b^{+} \mathrm{Gr}-1^{+}$MDSCs.

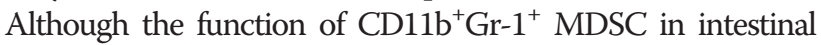
inflammation remains unclear, MDSCs accumulated in the bone marrow and spleen of DSS-exposed mice, and intravenous transplantation of DSS-induced splenic CD11b ${ }^{+} \mathrm{Gr}-1^{+}$ cells in $\mathrm{C} 57 \mathrm{Bl} / 6$ mice resulted in advanced mucosal healing [17]. We therefore conclude that the strong induction of $\mathrm{CD}_{11 \mathrm{~b}}{ }^{+} \mathrm{Gr}-\mathrm{1}^{+}$cells by sIgA contributed to the enhanced recovery from weight loss at later time points.

\section{Conclusions}

In conclusion, we tested the immunomodulatory potential of sIgA and bLf for improving the severity of DSS-induced murine colitis. SIgA but not bLf was identified as a colostral component that altered immune responses and promoted weight gain in colitic mice. Further studies are required to explore how this natural colostral compound modulates the colitis-induced immune cell redistribution.

\section{Methods}

Mice

Female outbred NMRI mice were purchased from Harlan Winkelmann GmbH (Melderslo, Netherlands) at the age of four to six months. They received standard food and water ad libitum. Mice aged eight to twelve months (average body weight $30 \mathrm{~g}$ ) were randomly assigned to different experimental groups. All animal experiments were performed in compliance with the German animal protection law (TierSchG BGBI S. $1105 ; 25.05 .1998)$ and were approved by the local commitee on the ethics of animal experiments of the University of Rostock (Landesamt für Landwirtschaft, Lebensmittelsicherheit und Fischerei Mecklenburg-Vorpommern) under permit number 2007/06/14;LALLFM-V/TSD/7221.3-1.1-059/08.

\section{Colostrum, lactoferrin and secretory immunoglobulin a}

For the therapeutic setting, BC powder (SANIMALIS, Heinsberg, Germany) was skimmed, pasteurized, and freeze-dried to ensure minimum denaturation of immunoglobulins and nutrients. The total protein content of the colostrum preparation was $60-70 \mathrm{~g} / 100 \mathrm{~g}$.

The BC (SANIMALIS) solution used for prophylactic treatment was skimmed, casein-free and sterile-filtered. The concentrations of immunoglobulin and other major ingredients were as previously described [5]. The total protein content was $7.25 \mathrm{~g} / 100 \mathrm{ml}$ (carbohydrate $0.2 \mathrm{~g} / 100 \mathrm{ml}$, fat $<0.01 \mathrm{~g} / 100 \mathrm{ml})$.

BLf was purified from bovine, and sIgA from human colostrum. IgG was isolated from human serum. All therapeutic agents were purchased from Sigma-Aldrich (Taufkirchen, Germany). Bovine BSA (Sigma-Aldrich) served as control.

\section{Induction of colitis}

Acute colitis was induced by DSS, as previously described [28]. Briefly, DSS (36-50 kDa; MP Biomedicals, Eschwege, Germany) was dissolved in sterilized tap water and presented to the mice at a final concentration of $5 \%$ for seven days. Fresh DSS solution was provided every second day.

\section{Therapeutic treatment protocol}

All therapeutic interventions were initiated from day 3 after starting DSS exposure until the end of the experiment (day 15). Either $20 \mathrm{mg} / \mathrm{kg}$ bw $\mathrm{BC}$ powder $(\mathrm{BC}, \mathrm{n}=6)$, $1 \mathrm{mg} / \mathrm{kg}$ bw sIgA (sIgA, $\mathrm{n}=6$ ), IgG (IgG, $\mathrm{n}=6), 150 \mathrm{mg} / \mathrm{kg}$ bw bLf (bLf, $n=5)$ or protein control (BSA, $n=5)$ were dissolved in physiological sodium chloride solution $(0.9 \%$ $\mathrm{NaCl}$ ) and given to each mouse in a final volume of $100 \mu \mathrm{l}$ daily by oral gavage. DSS-treated negative controls received $100 \mu \mathrm{l} \mathrm{NaCl}$ (DSS, $\mathrm{n}=8$ ). Physiological values were obtained from animals with no intervention (untreated, $n=6-8)$.

\section{Prophylactic treatment protocol}

One hundred $\mu$ l of pure $\mathrm{BC}(\mathrm{n}=6)$ was given to the mice orally by gavage daily for 14 days. All prophylactic treatments were initiated two weeks prior to colitis induction. SIgA and IgG were dissolved in $\mathrm{NaCl}$. Each mouse received $2 \mathrm{mg} / \mathrm{kg}$ bw $\operatorname{sIgA}(n=8)$ or $\operatorname{IgG}(n=8)$ in final volume of $100 \mu \mathrm{l}$ daily for 14 days by oral gavage.

\section{Clinical evaluation of colitis}

After starting DSS exposure at day 1, the mice were weighed daily until the end of the experiment at day 15 . Weight loss during the induction phase of colitis was observed from day 1 to day 7 (day $1=100 \%$ ), whereas the recovery phase was defined as weight gain after stopping DSS until the end of the experiment from day 8 to day 14 (day $8=100 \%$ ). Stool consistency was checked for diarrhea and feces were screened for blood during the acute inflammation phase of colitis from day 1 to day 7 (therapeutic protocol) or from day 1 to day 14 (prophylactic protocol) using a HemoCARE occult blood detection kit (Care Diagnostica, Voerde, Germany). DAI was determined according to Cooper et al. (1993) with minor modifications, by scoring changes in fecal blood, and stool consistency, as shown in Additional file 3 [29]. 


\section{Colon histology}

Mice were killed on day 15 after starting DSS. At autopsy, whole colons were removed and their lengths were measured. The colons were unrolled and divided longitudinally into two parts. One part was fixed and embedded in paraffin. Sections were stained with hematoxylin and eosin. The degree of colonic inflammation was analyzed by a pathologist in a blinded fashion, according to the scoring system originally described by Cooper et al. (1993) as shown in Additional file 4 [29].

\section{Flow cytometry}

Flow cytometry was performed on leukocytes from peripheral blood, spleens, and mesenteric lymph nodes as described previously [5]. Briefly, leukocytes were labeled using the following fluorescein isothiocyanate (FITC)- and phycoerythrin (PE)-conjugated anti-mouse monoclonal antibodies (mAbs) at the appropriate concentrations: CD3 $\varepsilon$ FITC, CD19 FITC, $\gamma \delta$ TCR PE (ImmunoTools, Fiesoythe, Germany), CD11b FITC, CD11c FITC, CD4 PE, CD8 PE; Gr-1 PE (Miltenyi Biotech, BergischGladbach, Germany), CD83 PE (eBioscience, Frankfurt, Germany). Negative controls consisted of lymphocytes stained with the appropriate isotype controls. Myeloidderived suppressor cells (MDSC) were defined as CD11b ${ }^{+}$ $\mathrm{Gr}-1^{+}$. Subsets of these cell populations were detected by gating on the $\mathrm{CD} 11 \mathrm{~b}^{+} \mathrm{Gr}-1^{\text {+high }}, \mathrm{CD} 11 \mathrm{~b}^{+} \mathrm{Gr}-1^{\text {+intermediate }}$, or $\mathrm{CD} 11 \mathrm{~b}^{+} \mathrm{Gr}-1^{+ \text {low }}$ fraction, definable by varying expression intensity. Samples were analyzed on a FACSCalibur Cytometer (BD Pharmingen) using CellQuest software and gating on total leukocytes (BD Biosciences, Mountain View, CA USA). Relative numbers are given.

\section{Statistics}

Values are reported as the mean \pm standard deviation (SD). To ensure reproducibility, experiments were repeated twice with three to four mice per group (except therapeutic experiment group DSS + bLf and DSS + BSA). Data from separate experiments were combined for statistical analysis and presentation in figures and tables. Owing to small sample sizes, group and time effects of clinical parameters (weight loss, DAI) were analyzed by a nonparametric oneway ANOVA model for repeated measurements using SAS 9.2 software [30]. To analyze the impact of DSS-colitis on histological parameters (cell infiltration and distribution, colon length) we first compared between untreated and $\mathrm{NaCl}$ groups. To analyze the influence of the treatment during the course of colitis, comparison was made between $\mathrm{NaCl}$ and the susceptive treatment group (BC, sIgA, and bLf). For the impact of BC and sIgA, we used BSA as appropriate protein control. To analyze whether observed immunoglobulin-induced effects are specific for sIgA, we used IgG as control. Analyses were performed with the parameter-free Mann Whitney $U$-test using SPSS software
[31]. $\mathrm{P}<0.05$ was considered the criterion for statistical significance.

\section{Additional files}

Additional file 1: Figure S1. Influence of therapeutics on colon length (A) and histological score (B) of DSS-induced colitis. Figure S1 shows the influence of therapeutically applied BC, slgA, bLf, control protein IgG, and BSA on histological severity of DSS-induced colitis. Colon length (A) and histological score (B) were analyzed at day 15 after starting DSS-exposure as indicated in the methods section. Values are means $\pm S D(A)$ or medians as horizontal line (B), of $n=12$ (Untreated), $n=8(\mathrm{NaCl}), n=6$ $(\operatorname{lgG}), n=5(\operatorname{slg} A, B C, b L f)$, and $n=4-5(B S A)$ mice. * $P<0.01$ vs. Untreated Mann Whitney U-test.

Additional file 2: Figure S2. Influence of prophylactic-applied therapeutics on histological severity of DSS-induced colitis. Figure S2 shows the histological severity of DSS-induced colitis following prophylactic application of BC, slgA, and control protein lgG. Values are shown as medians (horizontal line) of $n=6$ (slgA, BC), and $n=5$ (IgG) mice.

Additional file 3: Table S1. Disease activity index after DSS-exposure. Table $\mathbf{S 1}$ shows the scoring of the disease activity index after DSS exposure modified according to Cooper HS, Murthy SN, Shah RS, Sedergran DJ: Clinicopathologic study of dextran sulfate sodium experimental murine colitis. Lab Invest 1993; 69:238-249. The disease activity index is determined by summing the scores for weight loss, occult blood/gross bleeding, and stool consistency (maximal score $=10$ ). Slightly positive stool was defined as incomplete colored occult blood test. Positive occult blood test was defined as complete, intensive colored occult blood test. Gross bleeding was defined as fresh, visible blood on the fur around the anus. Normal stool is defined as well-formed, compact pellets, loose stool is defined as a pasty but formed stool, and diarrhea is defined as liquid stool.

Additional file 4: Table S2. Histological scoring of DSS-exposed mouse colons. Table S2 shows the histological scoring of DSS-exposed mouse colons. Modified according to Cooper HS, Murthy SN, Shah RS, Sedergran DJ: Clinicopathologic study of dextran sulfate sodium experimental murine colitis. Lab Invest 1993, 69:238-249. Tissue sections were scored separately for the amount and extent of inflammation, the amount of crypt damage, or regeneration and the percentage of involved tissue. The total histological score was generated by adding the product of the grade and the involvement of each feature to a maximum value of 40 .

\section{Abbreviations}

BC: Bovine Colostrum; BSA: Bovine Serum Albumin; bLf: bovine Lactoferrin; CAM: Complementary and Alternative Medicine; DAl: Disease Activity Index; DSS: Dextran Sulfate Sodium; hLf: human Lactoferrin; IBD: Inflammatory Bowel Diseases; IgG: Immunoglobulin G; LPS: Lipopolysaccharide; slgA: secretory Immunoglobulin A.

\section{Competing interests}

The authors declare that they have no competing interests.

\section{Authors' contributions}

$\mathrm{PB}$ and $\mathrm{CK}$ designed the research; PB and EZ conducted the research and analyzed the data. PB and SK performed the statistical analyses. PB, CM and CK wrote the paper and have primary responsibility for its final content. All authors read and approved the final manuscript.

\section{Acknowledgements}

We thank the late Dr. Joerg Emmrich for his helpful conversations about this work. All of those who knew him will miss his collegiality and wise advice. We acknowledge Dr. Horst Nizze's help with scoring the histological changes of DSS-exposed colons and Julia Glamann for her excellent technical assistance. This study was financially supported by the research grant for complementary medicine in IBD of the "Deutsche Crohn und Colitis Vereinigung", DCCV e.V. 


\section{Author details}

'Division of Gastroenterology, Department of Medicine II, University of Rostock, Rostock 18057, Germany. ${ }^{2}$ Department of Immunology, Project group "Extracorporal Immunomodulation", Fraunhofer Institute for Cell Therapy and Immunology, Rostock 18057, Germany. ${ }^{3}$ Centre for Coordination of Clinical studies, University of Rostock, Rostock 18057, Germany. ${ }^{4}$ Department of General, Vascular, Thoracic and Transplantation Surgery, Section of Molecular Oncology and Immunotherapy, University of Rostock, Rostock 18057, Germany

Received: 6 September 2012 Accepted: 1 February 2013 Published: 20 February 2013

\section{References}

1. Triantafillidis JK, Merikas E, Georgopoulos F: Current and emerging drugs for the treatment of inflammatory bowel disease. Drug Des Devel Ther 2011, 5:185-210.

2. Langmead L, Rampton DS: Review article: complementary and alternative therapies for inflammatory bowel disease. Aliment Pharmacol Ther 2006, 23:341-349.

3. Playford RJ, Macdonald CE, Johnson WS: Colostrum and milk-derived peptide growth factors for the treatment of gastrointestinal disorders. Am J Clin Nutr 2000, 72:5-14.

4. Solomons NW: Modulation of the immune system and the response against pathogens with bovine colostrum concentrates. Eur J Clin Nutr 2002, 56(Suppl 3):24-28.

5. Bodammer P, Maletzki C, Waitz G, Emmrich J: Prophylactic application of bovine colostrum ameliorates murine colitis via induction of immunoregulatory cells. J Nutr 2011, 141:1056-1061.

6. Brandtzaeg P, Carlsen HS, Halstensen TS: The B-cell system in inflammatory bowel disease. Adv Exp Med Biol 2006, 579:149-167.

7. Thoree VC, Golby SJ, Boursier L, Hackett M, Dunn-Walters DK, Sanderson JD, Spencer J: Related IgA1 and IgG producing cells in blood and diseased mucosa in ulcerative colitis. Gut 2002, 51:44-50.

8. Murthy AK, Dubose CN, Banas JA, Coalson JJ, Arulanandam BP: Contribution of polymeric immunoglobulin receptor to regulation of intestinal inflammation in dextran sulfate sodium-induced colitis. J Gastroenterol Hepatol 2006, 21:1372-1380.

9. Carbonare CB, Carbonare SB, Carneiro-Sampaio MM: Secretory immunoglobulin a obtained from pooled human colostrum and milk for oral passive immunization. Pediatr Allergy Immunol 2005, 16:574-581.

10. Sawai T, Goldstone N, Drongowski RA, Coran AG, Harmon CM: Effect of secretory immunoglobulin a on bacterial translocation in an enterocytelymphocyte co-culture model. Pediatr Surg Int 2001, 17:275-279.

11. Actor JK, Hwang SA, Kruzel ML: Lactoferrin as a natural immune modulator. Curr Pharm Des 2009, 15:1956-1973.

12. Buccigrossi V, de Marco G, Bruzzese E, Ombrato L, Bracale I, Polito G, Guarino A: Lactoferrin induces concentration-dependent functional modulation of intestinal proliferation and differentiation. Pediatr Res 2007, 61:410-414.

13. Debbabi H, Dubarry M, Rautureau M, Tomé D: Bovine lactoferrin induces both mucosal and systemic immune response in mice. J Dairy Res 1998, 65:283-293.

14. Sfeir RM, Dubarry M, Boyaka PN, Rautureau M, Tomé D: The mode of oral bovine lactoferrin administration influences mucosal and systemic immune responses in mice. J Nutr 2004, 134:403-409.

15. Håversen LA, Baltzer L, Dolphin G, Hanson LA, Mattsby-Baltzer I: Anti-inflammatory activities of human lactoferrin in acute dextran sulphate-induced colitis in mice. Scand I Immunol 2003, 57:2-10.

16. Togawa J, Nagase H, Tanaka K, Inamori M, Nakajima A, Ueno N, Saito T, Sekihara $\mathrm{H}$ : Oral administration of lactoferrin reduces colitis in rats via modulation of the immune system and correction of cytokine imbalance. J Gastroenterol Hepatol 2002, 17:1291.

17. Zhang R, Ito S, Nishio N, Cheng Z, Suzuki H, Isobe Kl: Dextran sulphate sodium increases splenic $\mathrm{Gr} 1(+) \mathrm{CD} 11 \mathrm{~b}(+)$ cells which accelerate recovery from colitis following intravenous transplantation. Clin Exp Immunol 2011, 164:417-427.

18. Fischer R, Debbabi H, Blais A, Dubarry M, Rautureau M, Boyaka PN, Tome D: Uptake of ingested bovine lactoferrin and its accumulation in adult mouse tissues. Int Immunopharmacol 2007, 10:1387-1393.
19. Warny M, Fatimi A, Bostwick EF, Laine DC, Lebel F, LaMont JT, Pothoulakis C, Kelly CP: Bovine immunoglobulin concentrate-clostridium difficile retains $C$ difficile toxin neutralising activity after passage through the human stomach and small intestine. Gut 1999, 44:212-217.

20. Hirotani $Y$, Ikeda K, Kato R, Myotoku M, Umeda T, ljiri Y, Tanaka K: Protective effects of lactoferrin against intestinal mucosal damage induced by lipopolysaccharide in human intestinal caco-2 cells. Yakugaku Zasshi 2008, 128:1363-1368.

21. Tsuchiya T, Fukuda S, Hamada H, Nakamura A, Kohama Y, Ishikawa H, Tsujikawa K, Yamamoto H: Role of gamma delta T cells in the inflammatory response of experimental colitis mice. J Immunol 2003, 171:5507-5513.

22. Giacomelli R, Parzanese I, Frieri G, Passacantando A, Pizzuto F, Pimpo T, Cipriani P, Viscido A, Caprilli R, Tonietti G: Increase of circulating gamma/ delta T lymphocytes in the peripheral blood of patients affected by active inflammatory bowel disease. Clin Exp Immunol 1994, 98:83-88.

23. Kühl AA, Pawlowski NN, Grollich K, Blessenohl M, Westermann J, Zeitz M, Loddenkemper C, Hoffmann JC: Human peripheral gammadelta T cells possess regulatory potential. Immunology 2009, 128:580-588.

24. Boismenu R, Havran WL: Modulation of epithelial cell growth by intraepithelial gamma delta T cells. Science 1994, 266:1253-1255.

25. Komano H, Fujiura Y, Kawaguchi M, Matsumoto S, Hashimoto Y, Obana S, Mombaerts P, Tonegawa S, Yamamoto H, Itohara S, Nannot M, Ishikawat H: Homeostatic regulation of intestinal epithelia by intraepithelial gamma delta T cells. Proc Natl Acad Sci 1995, 92:6147-6151.

26. Kühl AA, Loddenkemper C, Westermann J, Hoffmann JC: Role of gamma delta T cells in inflammatory bowel disease. Pathobiology 2002-2003, 70:150-155.

27. Kühl AA, Pawlowski NN, Grollich K, Loddenkemper C, Zeitz M, Hoffmann JC: Aggravation of intestinal inflammation by depletion/deficiency of gammadelta T cells in different types of IBD animal models. J Leukoc Biol 2007, 81:168-175.

28. Okayasu I, Hatakeyama S, Yamada M, Ohkusa T, Inagaki Y, Nakaya R: A novel method in the induction of reliable experimental acute and chronic ulcerative colitis in mice. Gastroenterology 1990, 98:694-702.

29. Cooper HS, Murthy SN, Shah RS, Sedergran DJ: Clinicopathologic study of dextran sulfate sodium experimental murine colitis. Lab Invest 1993, 69:238-249.

30. Brunner E, Domhof S, Langer F: Nonparametric analysis of longitudinal data in factorial experiments. In Probability and Statistics. New York: John Wiley \& Sons; 2002.

31. Mann HB, Whitney DR: On a test of whether one of Two random variables is stochastically larger than the other. Annals Math Stats 1947, 18:50-60.

\section{doi:10.1186/1471-2172-14-10}

Cite this article as: Bodammer et al:: Alteration of DSS-mediated immune cell redistribution in murine colitis by oral colostral immunoglobulin. BMC Immunology 2013 14:10.

\section{Submit your next manuscript to BioMed Central and take full advantage of:}

- Convenient online submission

- Thorough peer review

- No space constraints or color figure charges

- Immediate publication on acceptance

- Inclusion in PubMed, CAS, Scopus and Google Scholar

- Research which is freely available for redistribution 